\title{
Anti-Conceptualism and the Objects of Knowledge and Belief
}

\author{
Menno Lievers \\ Departement voor Filosofie en Religiewetenschap, \\ Universiteit Utrecht, Utrecht, Netherlands \\ m.lievers@uu.nl
}

\begin{abstract}
Michael Ayers's Knowing and Seeing: Groundwork for a New Empiricism is a rich and detailed development of two ideas. The first is that perception presents reality to us directly in a perspicuous way. We thus acquire primary knowledge of the world: "knowledge gained by being evidently, self-consciously, in direct cognitive contact with the object of the knowledge." (Ayers 2019, 63) The second idea is that concepts are not needed in perception. In this article, the author examines Ayers's view. The author proceeds as follows: In the first section, he identifies the target of Ayers's attacks, conceptualism. He then describes why many philosophers have felt this conceptualist view to be attractive. In the next section, he discusses Ayers's criticisms of conceptualism in an attempt to disentangle these criticisms from the statement of his positive view, which the author discusses in the following section. He ends by describing some problems for Ayers's positive position that are, so he argues, the result of his vehement opposition to conceptualism.
\end{abstract}

\section{Keywords}

perception - knowledge - belief - conceptualism 
[S]ensory or perceptual content and semantic or conceptual content are incommensurable.

AYERS 2O19, 77

\section{Introduction}

Perception yields knowledge. Within the paradigm of the analysis of knowledge as 'justified true belief', propositions can be said to be known, if they are justified, true and believed. Propositions that constitute knowledge thus constitute a sub-class of beliefs.

In the first chapter of his book, that is written jointly with Maria Rosa Antognazza, Michael Ayers shows that in the past, philosophers treated our knowledge faculty as a different and separate mental faculty from our belief faculty. Traditionally, the term knowledge was much narrower in scope than what is nowadays called 'knowledge'. According to the traditional view, we have only knowledge of what is immediately and in itself evident.

For Ayers, this is a source of inspiration for his own epistemology. His book Knowing and Seeing is woven out of two threads. The first, positive thread is the development of his own epistemology, which is markedly different from mainstream contemporary epistemology. Starting point is a description of the phenomenology of perception. In perception, Ayers claims, we are aware of our environment as our environment, and we are at the same time perceptually aware of how it is that we are aware of it. Perception is perspicuous. Objects are in perception "directly 'presented' to the knower, rather than being merely represented." (Ayers 2019, 62) Perception is the foundation for what Ayers calls 'primary knowledge'. The term 'secondary knowledge' Ayers reserves for knowledge that is not perspicuous, for instance, things we know on the basis of inferences to the best explanation.

He distinguishes both kinds of knowledge from belief, although he does not follow the tradition in claiming that knowledge and belief do not overlap, nor is his view that they are the products of different faculties. On the contrary, Ayers maintains that they both are forms of thinking with assent. This differential aspect of his epistemology comes to the fore in the fourth chapter, in which he discusses the objects of knowledge. According to Ayers, objects 
of knowledge are not propositions, but items in the real world, like states of affairs, events and material entities.

The second, negative thread in the argument developed in this book is anticonceptualism. According to Ayers, almost all of contemporary philosophy of perception and epistemology is infected with the virus of conceptualism.

The two threads, the phenomenology of perception and the anticonceptualist stance, come together in Ayers's discussion of the objects of knowledge. Faithful to his anti-conceptualism, Ayers defends the view that the objects of primary knowledge are states of affairs in reality and not propositions, as the majority of contemporary epistemologists maintain. He allows that beliefs still have, though not in all cases, propositions as their objects. I examine this view, in which the objects of knowledge are thus different entities than the objects of belief, in particular with an eye towards what happens when a belief becomes secondary knowledge or primary knowledge.

This discussion serves as a prelude to the presentation of a number of problems for Ayers's epistemology. It turns out that, as a consequence of the rejection of conceptualism in perception, perception no longer fits into the traditional propositional attitude psychological framework of thinking and reasoning. If this is correct, it seems that Ayers has to supplement his theory of perception with an alternative philosophy of mind.

\section{The Target: Conceptualism and its Advantages}

In order to get a clear view of the conceptualist position, that is the target of much of the argument in Ayers's book, it might be helpful to identify it more precisely: First, experiences are supposed to have content that can also be the content of acts of judging. Second, perceptual experiences are conceived of as propositional attitudes towards a conceptual content (see Crane 2009.) This view has been widely adopted. Byrne, for instance, writes: "[P]erceiving is very much like a traditional propositional attitude, such as believing or intending." (Byrne 2005, 232)

How come so many philosophers have adopted conceptualism as their position? One explanation could be that conceptualism meets what Peacocke has called 'the integration challenge' (Peacocke 1999, 1-2):

We have to reconcile a plausible account of what is involved in the truth of statements of a given kind with a credible account of how we can know those statements, when we do know them. [...] The concept of truth [...] must fit into an overall account of knowledge in a way that makes it intelligible how we have the knowledge [...] that we do have. 
The challenge we are now concerned with is how to account for perceptual knowledge. First, any account of knowledge has to say what the relation between knowledge and truth is. In doing so, such an account has to address the question of what truth is predicated. What is known must be true. So, what are the carriers of truth and falsity? Conceptualism returns a clear answer to his question: the carriers of truth and falsity are thoughts (propositions).

Second, Frege's distinction between first understanding and entertaining the proposition/thought and then, at a second stage, affirming or judging that the proposition as understood is true seems intuitively plausible. This is, perhaps, especially the case when we consider mathematical statements. First, we need to understand their meaning, then we can attempt to prove them. If we possess a proof of a statement, we are entitled to affirm its truth or falsity. Applied to perception, this model suggests the following: First we need to understand what we see, then we can proceed to use the content of that perception in a perceptual judgement. If perception involves the employment of concepts, there is a close similarity between understanding a statement and perception. Third, it has a clear (and demanding) picture of the justification of perceptual knowledge. The items that justify perceptual beliefs ought to be carriers of truth and falsity, because they are reasons for action. Fourth, conceptualism enables a smooth transition from mere belief to certain knowledge. If we accumulate more evidence, what was initially just a belief becomes knowledge. Fifth, the conceptualist analysis of judging constitutes the core/ basis of a comprehensive theory of mind, the computational representative theory of mind. (Fodor 1975)

\section{2 \\ An Interpretative Intermezzo: the Extent of Ayers's Anti-conceptualism and its Consequences}

It has been suggested that Ayers's account of perceptual knowledge can be interpreted along the lines of 'a recognitional model'. (Roessler 2020, 4) This recognitional model "accounts for perceptual knowledge in terms of the exercise of perceptual-recognitional abilities, that are [...] abilities to tell, that is, come to know, of things that are some way that they are that way from the way they appear to one or other of our sense modalities". (Millar 2019, viii) This interpretation is the result of wishful thinking. Ayers is committed to an allout anti-conceptualism, as is evident from his criticism of the conceptualist McDowell.

Ayers's first objection against McDowell immediately shows that he does not in any way subscribe to a kind of recognitional model. Recognition may sometimes affect how things appear to the senses, but does not determine how 
things appear to the senses. "Two people may see the same thing - a bird, a stone, a shape drawn on paper, or a colour - and see it in just the same way, although only one of them recognizes it as a cardinal bird, a flint, a rhombus, or puce." (Ayers 2019, 76) The difference between these two subjects is therefore not that different conceptual capacities have been exercised at the level of perception, but that they describe differently how the thing looks to them. (Ayers 2019, 76-77)

The second objection is the familiar one that concepts cannot capture the 'fine grain' of objects of experience. Ayers generalizes this objection into a fundamental claim: "sensory or perceptual content and semantic or conceptual content are incommensurable." (Ayers 2019, 77) He illustrates this incommensurability by comparing the way a picture or a photograph conveys information about a scene with the way a description does. These two ways of conveying information each possess their own criteria of determinacy that are completely different.

These objections to conceptualism show that Ayers does not adhere to the recognitional model, because according to that model, as Roessler (2020) notes:

[...] you come to know the animal is a tiger because you are able noninferentially to tell a tiger when you see one. Telling or recognizing something is a way of coming to know what sort of thing it is or what features or relations it has.

Ayers explicitly denies this: "[N]ot all perceptual 'knowledge that', still less all perceptual knowledge, involves recognition or classification under a determinate concept." (Ayers 2019, 106) Ayers is a radical non-conceptualist. ${ }^{1}$

In the fourth chapter of Ayers's book, entitled "Internal and External Objects of Cognition", the two threads, the phenomenology of perception and anticonceptualism, come together. The positive thread culminates in the claim that the objects of knowledge are states of affairs or events in reality, which implies the victory of the negative thesis that the objects of knowledge are

1 I emphasize this, as does Roessler (2020), although the phrase 'non-conceptual' does not occur in Ayers's book; yet it seems a helpful characterisation of his position. 
not propositions. This is the most radical claim of the book, since it is widely assumed that the object of knowledge is a proposition. ${ }^{2}$

At the outset of his argument, Ayers, therefore, is in the following predicament: if we want to reject the view that the objects of (perceptual) knowledge are propositions, we have to provide an alternative account of the role of truth in (perceptual) knowledge in order to meet the integration challenge.

Ayers's route towards an answer to this question takes as its point of departure a rejection of the customary alignment of knowledge and belief. In the conceptualist tradition, these mental states are conceived of as two distinct propositional attitudes towards a proposition that can also be the content of an assertion. Knowledge, on this view, is a species of belief, namely, those beliefs that have contents that are true and justified.

Ayers rejects this assimilation. He also does not endorse the traditional epistemology, that stems from Plato, according to which knowledge and belief are two distinct mental faculties. Instead, he argues, we should conceive of 'knowledge' as primarily a mental state in which we have direct cognitive contact with reality. That mental state is completely perspicuous to itself, in the sense that it is evident for the subject that she is in this mental state, because she is in causal contact with the object the mental state is about. The knowing subject thus knows that she knows.

This description fits most closely perception, which therefore is, to use Ayers's phrase, primary knowledge. Ayers follows the tradition in reserving this term for knowledge that is "[...] in itself evident and independent from extraneous reasons". (Ayers 2019, 26) From modelling primary knowledge on perception Ayers derives a causal principle. In perception we know that the object we perceive is also the cause of our experience; likewise, Ayers $(2019,96)$ states:

The principle that the object of knowledge is also a significant cause of that knowledge suggests that the object of an ascription of knowledge that $\mathrm{S}$ is $\mathrm{P}$ is the event or state of affairs, S's being P, rather than either the proposition or the fact that $\mathrm{S}$ is $\mathrm{P}$, neither of which are ontologically satisfactory causes.

2 A notable exception is Hanoch Ben Yami (1997). For the orthodox view, see, for instance, Williamson 2000, 21. That there is something odd about the traditional view that the objects of knowledge are propositions has already been noted by Prior $\left(1971,15^{-16}\right)$. 
So, from the start of the argument, it is clear what its conclusion will be. What are the other arguments that support this conclusion? - First, Ayers establishes that ordinary language shows that knowledge and belief have different objects. Knowledge that $\mathrm{S}$ is $\mathrm{P}$ is knowing 'to on'. "Knowing is a relation of the knower to what it is in the world that is known." (Ayers 2019, 99) Second, this knowledge relation is irreducible; just like the mental states of love and regret, it cannot exist without something actual being known. Third, those who maintain that in perception the fundamental phenomenon is that of seeing that such and such is the case are misled by language. In particular, they project the description of what is seen onto what is seen. (Ayers 2019, 113)

Ayers then rejects both propositions and facts as candidates for being the object of knowledge, mainly on the basis of the causal principle. They are too abstract to be able to play any kind of causal role in acts of perception. Propositions are furthermore disqualified, because they are also too abstract to be evidence for any judgement about the world. For instance, when we want to establish that an accused is guilty, it is, duly considered, her actions themselves that make the accused guilty, rather than the descriptions of these actions. (Ayers 2019, 117)

Facts are, similarly, too abstract, because they are individuated by the propositions that describe them. They are, thereby "infected by the timelessness or 'eternity' of propositions." (Ayers 2019, 123) The conclusion does not come as a surprise: "Particular events and states of affairs are therefore significantly better candidates for being what in the world we have in the end 'latched onto' or apprehended when we have [primary] knowledge of the world." (Ayers 2019, 124)

Besides the cognitive mental state of primary knowledge, Ayers also recognizes a second cognitive mental state, which he calls 'secondary knowledge': things that are known on the basis of extraneous reasons. Between the two kinds of knowledge, there is a hierarchy: "[...] no one could have beliefs, and certainly no justified beliefs, if they had no knowledge, no one could have secondary knowledge unless they had some primary knowledge." (Ayers 2019, 36)

Ayers's account of knowledge thus has the following structure: Central is the mental state of primary knowledge, of which perceptual knowledge is the paradigm. Primary knowledge of abstract principles is explained in terms of perceptual knowledge. ${ }^{3}$ Whereas primary knowledge is direct, secondary knowledge is indirect, in the sense that it is indirectly derived via routes as diverse as testimony and inference to the best explanation. Then there is a third mental state, belief.

3 I return to this issue below. 
This account raises the question of how to distinguish in more detail than just by appealing to 'extraneous reasons', first, primary knowledge from secondary knowledge, second, primary knowledge from beliefs, and third, secondary knowledge from beliefs.

\subsection{Primary Knowledge versus Secondary Knowledge}

What distinguishes primary knowledge from secondary knowledge? Perceptual knowledge serves as the paradigm of primary knowledge. A subject has direct cognitive contact with his or her environment and perceives him or herself as having that very knowledge and how that is perceived. (Ayers 2019, 63, 185)

Secondary knowledge is knowledge whose evidence is derived from primary knowledge. Examples are testimony, instruction, knowledge by causal inferences. (Ayers 2019, 26) Ayers provides an example to make clearer what he means by the term 'secondary knowledge'. On the basis of footprints, droppings, a dung that is still warm, and knowledge of the local bears, a subject forms the true belief that a bear has recently passed through. Is this knowledge? According to Ayers it is, because the subject knows how she knows. "[T] he causal relation between object and knowledge or belief is perspicuous to the knower." (Ayers 2019, 66)

The treatment of the bear-example suggests that the difference between primary and secondary knowledge has a counterpart in mathematics, where direct proofs are distinguished from indirect proofs. As is well known, intuitionists only accept direct proofs of mathematical statements; similarly, Ayers only accepts direct cognitive contact and perspicuous awareness as primary knowledge.

\subsection{Primary Knowledge versus Belief}

The difference between primary knowledge and belief is, according to Ayers, not a qualitative but a categorical one. Primary knowledge involves direct cognitive contact with reality and is perspicuous. In an ascription of knowledge, one ascribes a cognitive and causal relation to an event or a state of affairs in reality. In an ascription of belief, one ascribes a cognitive relation to an intentional content, whether that is semantic, experiential or the content of a picture. (Ayers 2019, 101)

Knowledge and belief, therefore, can overlap and are not the product of distinct mental faculties. Both knowledge and belief are forms of thinking with assent. As it might be said, and as Zeno Vendler has argued for: "You know facts, but you believe propositions." (Vendler, 1972, 82-83) When an ascription of knowledge is appropriate, then an ascription of belief is so too. On other occasions, only an ascription of belief is appropriate. 


\subsection{Secondary Knowledge versus Belief}

The distinction between secondary knowledge and belief is more difficult to draw. If we examine Ayers's example of the footprints of the bear again, it seems as if we start with a belief or a hypothesis that is formed on the basis of perceptual knowledge of the footprints and the droppings. As Ayers (2019, 65 ) notes, when we accumulate more evidence, the belief turns into a piece of knowledge:

[W]e can see that one general condition of 'evidence' is fulfilled in that the inference itself charts the actual causal route from the state of affairs of which I have inferential knowledge, the recent presence of a bear, to the current indications that I now perceive and recognize. To that extent, I know how I know.

This suggests that the belief that there has been a bear, which is a propositional attitude directed towards a proposition, has been turned into a piece of knowledge that has as its object a fragment of reality, namely the state of affairs that there has been a bear.

Now it would be convenient if we could simply say that the objects of belief are propositions and the objects of knowledge states of affairs in reality. However, matters are not so straightforward, given Ayers's broad characterization of belief. We need a heterogeneous account of the objects of beliefs, since many of our beliefs concern existing persons or objects, which we need to know if we are in a position to form beliefs about them. That is, many of our beliefs presuppose knowledge.

We are now in a position to outline the epistemological theory Ayers has erected as an alternative to conceptualism. Perceptual knowledge, seeing, serves as the fundamental kind of knowledge, primary knowledge. If we possess primary knowledge, we have direct cognitive contact with reality, and this is perspicuous to us, in the sense that we know that we know the object perceived and how we know that. The content of experience is intimately related to the parts of reality that are presented to us in perception, because we are conscious of the fact that these objects are also the causes of what we see.

Beliefs are (or can be) directed at propositions, and they tell us more about what we think than about the world around us. Some beliefs, however, are, just like primary knowledge, world-directed. The term 'secondary knowledge' Ayers reserves for knowledge that is world-directed, but in which the evidence for it has been acquired indirectly, rather than immediately in an act of perception in which the object of knowledge is being perceived. 
A crucial consequence of this view of epistemology is that 'knowledge' gets redefined as a cognitive state of a subject. By eliminating concepts from the fundamental acts of perception that cognitive state can be referred to as a nonconceptual state. It is tempting to conceive of that state as an informational state. The challenge for epistemological theories of that kind has always been to give a convincing account of the connection between these cognitive states and the higher-order conceptual states. In the next section, I will formulate objections to Ayers's position that are all motivated by the fear that this transition of the cognitive state of perception to thinking in propositions is a serious problem.

\section{Problems for a Non-Conceptualist Phenomenology of Perception}

What are the consequences of replacing a conceptualist theory of perception by a realist non-conceptualist account of perception for the mainstream philosophy of mind, in which thinking is conceived as the entertaining of propositional attitudes towards propositions composed out of concepts? Does it require a rejection of the entire framework of propositional attitudes towards contents or can they cohere? In order to answer that question, I discuss a number of problems.

\subsection{The Transfer Problem}

As described above, Ayers employs two notions of knowledge: primary knowledge and secondary knowledge. On a naïve view of knowledge acquisition, a subject first forms a belief and then either falsifies or verifies this belief to such an extent that it becomes a justified belief that deserves to be called 'knowledge. How does Ayers describe this transition?

Let us study, with an eye towards this transition from belief to knowledge, his own example of the bear that was presented to make clear how and why we acquire secondary knowledge. What is going on in our mind, when we make the transitions Ayers envisages? First, we have primary knowledge of footprints, droppings, the warmth of the dung. The object of these pieces of primary knowledge are states of affairs in reality. On the basis of this evidence, we form the belief that a bear has passed by. Since we do not have a causal, cognitive relation with the state of affairs that there is a bear walking around, but only with the state of affairs that there are prints and dung, we have a belief that refers to the bear via knowledge by description, e.g. 'the bear that made these footprints'. This belief can be turned into secondary knowledge if we accumulate more evidence. But now it seems that Roessler's interpretation 
of Ayers's position as coming close to a recognitional model does seem not too far off in this case. (Roessler, 2020, 4-6) For the prints and the dung can only serve as justifiers, truth-makers, for the secondary knowledge that there is a bear if these things are recognized as prints and dung of a bear.

Secondary knowledge can turn into primary knowledge, for instance, in Ayers's example, when we suddenly encounter a bear walking in the gardens. Now it cannot be that somehow the thought that there is a bear in the vicinity that was known secondarily is replaced by the perspicuous awareness that there is a bear in front of us. There is no sharp separation between the primary knowledge that there is a bear and the thought that there is a bear. ${ }^{4}$

It seems then that whenever secondary knowledge turns into primary knowledge, the concepts required for entertaining the thought that is secondarily known are also involved. This can be denied, of course, if the prints and the dung of the bear cause a non-conceptual thought (content) about a bear in the vicinity that is the object of secondary knowledge. That object cannot be the state of affairs that there is a bear in the vicinity, because there is no direct cognitive, causal contact with that state of affairs. Now it could be maintained that there is indirect cognitive, causal contact via the prints and the dung of the bear, but then it seems inevitable to assign a role to recognitional capacities, e.g. 'these are footprints of a bear', which Ayers rejects. (Ayers 2019, 171)

\subsection{Abstract Knowledge}

Ayers also applies his account of primary knowledge to a priori knowledge. In Ayers 2019, 64, he claims that

we are in immediate cognitive contact with what is understood. The fact itself lies open to us, so to speak. We not only know it, but in virtue of the way we know it we know how we know it - that is, how we are related to it so as to know it. [...] There is no 'causal route' from abstract fact to thinker, but there is the awareness, not only of the fact (whatever such facts consist in), but of our understanding it. [...] paradigmatic, primary understanding is self-consciously understanding.

This quote invites an objection, namely that in the case of more complicated mathematical and logical statements, we first need to understand the abstract proposition, and subsequently find out or construct a proof to the effect that the proposition is true. As Dummett has emphasized on many occasions: we ought to distinguish knowing the proposition from knowing that

4 This touches on the debate between Ayers (2004), Ayers (2019, 76-78) and McDowell (2009). 
the proposition is true. It is precisely for this reason that Frege distinguished the content stroke from the judgement stroke in his symbolism. It is also an important argument to distinguish between Frege's notion of sense and the notion of linguistic meaning, which Frege introduced, among other reasons, for being able to account for the progress of mathematical understanding (see Burge 1990, 31). In these cases, it is not a possibility to perceive or take in at a glance that the necessary fact is true, for the understanding might as yet be incomplete. ${ }^{5}$ It seems difficult, if not impossible, to account for this phenomenon without granting that primary knowledge of abstract principles involves propositions.

\subsection{The KK-principle}

In the explanation of why primary knowledge is self-evident, the KK-principle plays a crucial role. It is the principle that if you know, you know that you know. Interpreted thus, the principle requires a meta-standpoint on the object-level of knowledge. The question then arises what the object of knowledge at this meta-level is. Discussions of the KK-principle simply take it for granted that it is the proposition that is known at the first level. (Das and Salow 2018, Byrne 2012, Greco 2014, Stalnaker 2015) Ayers, of course, cannot accept that propositions are the objects of knowledge, not even of meta-knowledge. He describes this meta-knowledge as follows (Ayers 2019, 63):

Conscious perceptual knowledge is such that those that have it not only have perceptual knowledge of their environment, but also perceptual knowledge that and of how they have that knowledge. They have that logically second-order knowledge without second-order reflection. They have what I have called 'primary knowledge', knowledge gained by being evidently, self-consciously, in direct cognitive contact with the object of the knowledge.

The object of first-order knowledge are states of affairs in reality. But what are the objects of the kind of second-order knowledge that is required for the KK-principle? Most defenders of the KK-principle argue that there is transparency; the thing that is transparent is a proposition. It seems that the notion of second-order knowledge confronts Ayers with a dilemma: He either accepts this functioning of the KK-principle or he does not. If he does, he concedes to conceptualism that concepts are involved in perception after all,

5 Ayers notes that it is controversial whether the use of the word fact is legitimate here. I would object to use the word 'fact' in logic and mathematics. 
namely at this second-order level. If he does not, he owes us an account of how the KK-principle is functioning; as things stand, we do not have an account of the rational linkages between the first-order level of knowledge and the second-order level. His suggestion seems to be that there is secondorder kind of perception involved, but more is needed, certainly in the light of the controversies surrounding the KK-principle (see, for instance, Williamson 2000, 114-119).

\subsection{The Integration Problem: Phenomenology of Perception and the Mind}

Any account of perception faces the problem of how to explain the truth of perceptual judgements. Another way of stating this has been done above in terms of Peacocke's 'integration challenge'. Where does truth come in? This raises the question of what the carriers of truth and falsity are in perception. In the contemporary literature, this question often is formulated as whether perceptual experience can provide reasons (see, for instance, Brewer 1999, 2018; Cunningham 2018). Cunningham (2018) explores the suggestion that the notion of reasons employed in perception can be broadened so as to include not only propositions but also objects of awareness. He does so to accommodate Davidson's claim that the only justification for a belief can be another belief (Davidson 1986). Since perceptual experiences are not beliefs, perceptual judgements cannot be justified. His examination can be read as an attempt to meet the integration challenge that conceives of the objects of knowledge as entities in reality in the way Ayers proposes.

Cunningham calls the claim that objects of awareness can function as reasons for perceptual beliefs the 'Truth-maker View'. The puzzle Davidson's slogan encapsulates is generated by the conjunction of four theses (Cunningham 2018, 257):

- Reasons Priority: perceptual knowledge is belief held in the light of perceptual reasons.

- The Doxastic Thesis: believing for a reason requires that one believes the proposition which is one's reason. "Reasons that are out there in one's environment [...] cannot be one's reasons for belief (or action)." (Cunningham 2018, 258)

- Belief-Independence: experiences are not beliefs.

- The Non-Inferential Thesis: perceptual knowledge is non-inferential.

The puzzle these theses entail is that perception cannot provide reasons for action, because perceptual experience is not a belief. One attempt to solve the puzzle is conceptualism, that saddles experience with the same 
content that can be the object of propositional attitudes. The Truth-Maker View Cunningham examines is motivated by the desire to meet the puzzle while conforming to Reasons Priority, without having to ascribe representational content to experience.

The main candidates for truth-makers are: states of affairs, events, objects and properties. Ayers mentions three of these as objects of primary knowledge (he does not mention properties). Each brings along its own problem, in particular that of providing a plausible ontology for these truth-makers.

Cunningham defends an argument against the entire idea that any of these truth-makers can provide reason for perceptual beliefs, the Explanatory Exclusion Argument (Cunningham 2018, 267):

( $\mathrm{P} 1$ ) If $\mathrm{S}$ believes that $\mathrm{p}$ for the reason that $\mathrm{R}$, then $\mathrm{S}$ 's belief that $\mathrm{p}$ is subject to a rationalizing explanation which has $\mathrm{R}$ as its explanans.

$\left(\mathrm{P}_{2}\right)$ The explanantia of rationalizing explanations are truths.

(C) If $S$ believes that $p$ for the reason that $R$, then $R$ is a truth.

Informally, the conclusion of the argument is that the reasons for which one believes that $\mathrm{p}$ are always true propositions, understood in the Fregean way $[\ldots]$.

This is not the place to examine Cunningham's attempted refutation of the claim that any of the truth-maker candidates can meet the requirements this argument imposes on them if they are to be reasons for perceptual beliefs. Cunningham $(2018,275)$ plausibly concludes that none of the items (states of affairs, events, objects, properties) are finely individuated enough

to count as factors which give how it is from the subject's own point of view so that their reason to believe that $\mathrm{O}$ is $\mathrm{F}$ is present as a reason to believe that [it is] so[.] [...] For if the explanans of the [...] explanation is just a particular or a state of affairs, then it won't be an element of the subject's point of view which is the appearance of a reason to believe that $O$ is $F$ to them, rather than any distinct member of the innumerably large set of propositions which are equally accurate ways of thinking about the particular or state of affairs in question.

Cunningham's conclusion is relevant for Ayers's position, because, as said above, the items he considers as potential truth-makers that can be reasons for belief are the same items Ayers considers to be the objects of knowledge 
(with the exception of properties). If Cunningham's critical analysis is correct, it seems, therefore, that Ayers cannot meet the integration challenge.

How fatal is this for Ayers's epistemology? The answer is radical. Ayers rejects the puzzle, not by rejecting the Doxastic Thesis that believing for a reason requires that one believes the proposition which either is, or else represents, one's reason but by rejecting the first premise. Cunningham writes: "The proponent of the Truth-Maker View is committed to Reasons Priority. As such, they want to explain why perception yields knowledge by appeal to the thought that perception provides reason for belief." (Cunningham 2018, 278) This is precisely what Ayers rejects: to possess perceptual knowledge is not giving and having reasons for believing what is believed. (Ayers 2019, 79) ${ }^{6}$

Given this rejection, we need to ask how Ayers does conceive of the relationship between perception and reason. On that question, Knowing and Seeing does not contain an answer. That Ayers does not address this issue has as a consequence that it is also unclear how he would meet the integration challenge. If one attempts to construct one on his behalf, it is difficult to see where to start, because the most crucial ingredient for such an account is missing: the carriers of truth and falsity. Neither in his exposition of perception nor in his theory of knowledge is there an indication of what exactly truth is predicated.

Now it would be a mistake to call this an oversight. Instead, it seems to me that Ayers's book can be seen as an endeavour to reverse the order in which constraints are put on either perception or reason. Standard attempts to describe the relationship between thought and perception impose constraints on perception to fit the deliverances of the senses into an account of thought. This approach leads to an assimilation of perception to thinking, as if to perceive is a kind of thought, which Burge has called an 'hyper-intellectualization' of perception (Burge 2010). If we follow Ayers, we should instead start with an account of perception that delivers constraints on an account of reasoning and thinking. ${ }^{7}$ This means that we need to supplement Ayers's phenomenology of perception with a radical empiricist philosophy of mind. Such an account might even be non-conceptualist. When criticizing McDowell's conceptualism for being unable to account for the intelligent behaviour of fish, Ayers (2019, 78) writes:

6 My paraphrase is more outspoken than the cautious formulation Ayers employs on this page, but I think it is justified by the anti-conceptualist tone of the book.

7 It has been suggested to me that Ayers's phenomenology inevitably leads to the continental tradition in philosophy. 
The action of the individual fish that was filmed carrying clams a significant distance to break them open, after considerable effort, against a favourite hard coral, or of the particular octopus that found a way to escape and confuse predatory sharks by covering itself with shells and seaweed, is surely plausibly taken be $[$ sic $]$ evidence of a level of intelligence and ingenuity once routinely denied to such creatures.

As is evident from this quote, Ayers ascribes intelligent thinking to the fish and the octopus, although they do not possess concepts. As a result, we need to develop an account of non-conceptualist thinking that explains their actions. It seems that, if we regard as compelling Ayers's phenomenology of perception, we are driven towards the obligation to develop a similar and fitting nonconceptualist account of human thinking. This is a speculative conclusion, but Ayers's uncompromising anti-conceptualism does not leave us with another option. Primary knowledge, Ayers's style, seems difficult, if not impossible to embed in a conceptualist theory of thought.

\section{Acknowledgments}

For extensive and helpful comments on an earlier draft of this article I would like to thank M.R. Ayers and A.S. Meincke.

\section{References}

Ayers, Michael 2004. "Sense Experience, Concepts and Content - Objections to Davidson and McDowell". In: Perception and Reality. From Descartes to the Present, edited by Ralph Schumacher, Paderborn: Mentis, 239-262.

Ayers, Michael 2019. Knowing and Seeing. Groundwork for a New Empiricism. Oxford: Oxford University Press.

Ben-Yami, Hanoch 1997. "Against Characterizing Mental States as Propositional Attitudes." Philosophical Quarterly 47, 84-89.

Brewer, Bill 1999. Perception and Reason. Oxford: Clarendon Press.

Brewer, Bill 2018. "Perceptual Experience and Empirical Reason." Analytic Philosophy $59(1), 1-18$.

Burge, Tyler 199o. "Frege on Sense and Linguistic Meaning". In: The Analytic Tradition, edited by David Bell and Neil Cooper, Oxford: Blackwell, 30-6o.

Burge, Tyler 2010. Origins of Objectivity. Oxford: Clarendon Press. 
Byrne, Alex 2005. "Perception and Conceptual Content". In: Contemporary Debates in Epistemology, edited by Ernest Sosa and Matthias Steup, Oxford: Blackwell, 231-250. Byrne, Alex 2012. "Knowing What I See." In: Introspection and Consciousness, edited by Declan Smithies and Daniel Stoljar, Oxford: Oxford University Press, 183-210.

Crane, Tim 20o9. "Is Perception a Propositional Attitude?" Philosophical Quarterly 59, $45^{2-469}$.

Cunningham, J.J. 2018. “Are Perceptual Reasons the Objects of Perception?” In: In the Light of Experience - Essays on Reasons and Perception, edited by Johan Gersel, Rasmus T. Jensen, Morton S. Thanning and Soren Overgaard, Oxford: Oxford University Press, 256-28o.

Das, Nilanjan and Salow, Bernard 2018. "Transparency and the Kк Principle." Nô̂s 52 (1), 3-23.

Davidson, Donald 1986. "A Coherence Theory of Truth and Knowledge". In: Truth and Interpretation, edited by Ernest LePore, Oxford: Clarendon Press, 307-319.

Fodor, Jerry A. 1975. The Language of Thought. New York: Thomas Y. Crowell.

Greco, Dan 2014. “Could кк Bе ок?” Journal of Philosophy 111, 169-197.

McDowell, John 2009. "Conceptual Capacities in Perception”. In: Having the World in View. Essays on Kant, Hegel, and Sellars. Cambridge, Mass.: Harvard University Press, 127-144.

Millar, Alan 2019. Knowing by Perceiving. Oxford: Oxford University Press.

Peacocke, Christopher 1999. Being Known. Oxford: Clarendon Press.

Prior, A.N. 1971. Objects of Thought. Oxford: Clarendon Press.

Roessler, Johannes 2009. "Perceptual Experience and Perceptual Knowledge." Mind 118, 1013-1041.

Roessler, Johannes 2020. Book Review Knowing and Seeing: Groundwork for a New Empiricism, by Michael Ayers (ch. 1 co-authored with Maria Rosa Antognazza). Mind. [Forthcoming in print. Online first published August 2, 2020; https://doi. $\operatorname{org} / 10.1093 / \mathrm{mind} /$ fzaao41].

Stalnaker, Robert 2015. "Luminosity and the K K Thesis." In: Externalism, Self-Knowledge, and Skepticism, edited by Sanford C. Goldberg, Oxford: Oxford University Press, 19-40.

Vendler, Zeno 1972. Res Cogitans: An Essay in Rational Psychology. Ithaca, NY: Cornell University Press.

Williamson, Timothy 2000. Knowledge and Its Limits. Oxford: Oxford University Press. 